\title{
VIRAL INFECTIONS OF THE HUMAN NERVOUS SYSTEM* \\ Classification and General Considerations
}

By Albert B. Sabin, M.D.

Professor of Research Pediatrics, University of Cincinnati College of Medicine. The Children's Hospital Research Foundation, Cincinnati, Ohio

The diseases of the human nervous system for which a virus etiology has been definitely established may be classified into those which have their basic reservoir in human beings and, therefore, are world-wide in distribution, and those whose basic reservoir is extra-human, with consequent variations in distribution in different parts of the world (Table $\mathrm{r}$ ). The most important disease in the first category is unquestionably poliomyelitis. The other viruses, which affect the nervous system and whose reservoir is in human beings, are those of mumps (parotitis), herpes simplex and lymphogranuloma venereum.

Although the occurrence of mumps meningitis has been suspected for many years on clinical grounds, the very recent development by Enders and his associates ${ }^{1,2}$ of satisfactory serologic methods for diagnosis not only established the truth of this suspicion, but provided unequivocal proof that the nervous system is not infrequently

TABLE I

VIRAL INFEctions OF THE Human Nervous System

(Classification based on information available in January r949 $\dagger$ )

A. Diseases and Viruses Known

I. Basic reservoir in human beings; world-wide in distribution.

(a) Sporadic and epidemic: Poliomyelitis.

(b) Sporadic:

Mumps (parotitis).

Herpes simplex.

Lymphogranuloma venereum.

2. Basic reservoir extra-human; few widespread, most limited in distribution.

(a) Arthropod-borne encephalitides:

St. Louis.

Western equine.

Eastern equine.

Venezuelan equine.

Japanese B.

Russian tick-borne.

Louping III.

(b) Transmitted by animal secretions or excreta:

Rabies.

Lymphocytic choriomeningitis.

(Pseudolymphocytic choriomeningitis?).

$B$ virus (monkey).

B. Virus Etiology Possible, but Viruses little KNOWN OR UNKNOWN

Von Economo's encephalitis lethargica.

† Since this paper was prepared for presentation at the Fourth International Neurological Congress, it has become necessary to consider the inclusion of a new virus in this classification. This virus has been recovered from the stools and nasopharyngeal secretions of patients with the clinical diagnosis of poliomyelitis. The virus is characterized by its pathogenicity for suckling, but not older, mice in which it produces a myositis resulting in paralysis; although it multiplies in the brain as well as in most other tissues of the suckling mice, there is no histological evidence of neuronal involvement. The virus is not pathogenic for monkeys and is distinct from the viruses of poliomyelitis. There are multiple immunological types of the new virus, and it has also been recovered from urban sewage and non-biting, 'filth' flies separately and in conjunction with poliomyelitis virus. Whether or not the basic reservoir of this with poliomyelitis virus. Whether or not the basic reservoir of this
new virus is limited to human beings is not as yet known. It has
Herpes zoster.

Australian ' $\mathrm{X}$ ' (may have been Japanese B).

C. Neurotropic Viruses Known, but Diseases of $\varnothing \overrightarrow{0}$ Human Nervous System UnKNown

Viruses discovered in:

Africa: West Nile, Bwamba fever, Semliki Forest, Bunyamwera.

South America: Ilheus, Columbia 'mosquito' viruses.

Virus discovered in:

North America: California 'mosquito' virus (Hammon and Reeves).

North America + Africa: Apparently same virus rediscovered several times and described under names of 'Columbia SK,' MM poliomyelitis, EMC (encephalomyocarditis), Mengo encephalomyelitis.

D. Diseases Sometimes Grouped with Virus INFECTIONS Without AdeQuate Evidence

Infectious polyneuritis (Guillain-Barré syndrome).

Post-infection and post-vaccination (demyelinating) encephalitis: Measles, varicella, rubella, vaccinia, variola, mumps, 'influenza,' etc.

Acute hemorrhagic encephalitis.

not as yet been recovered from the human nervous system, but patients harbouring this virus have exhibited pleocytosis. The chief importance of this virus, thus far, is as a frequent cause of the ' aseptic meningitis syndrome' occurring during the very months of the year when it could most readily pass for non-paralytic poliomyelitis. However, simple virological and serological procedures are now available for the laboratory diagnosis of infection with this are now available for the laboratory diagnosis of infection with this
virus. There is as yet no unequivocal evidence that the new virus can produce paralysis in human beings (either due to muscle lesions similar to those in suckling mice or by some other mechanism). It is possible that a patient may be infected simultaneously with both poliomyelitis virus and the new virus, and the ultimate pathogenic potentialities of the new virus can be elucidated only by additional observations in human beings $(58,59,60,61$ and personal communications from Dr. J. L. Melnick).

* Opening paper delivered to the Fourth International Congress of Neurology in Paris, September r949. It is reproduced here by kind permission of the Editors of the Proceedings of the Congress. 
attacked by the mumps virus in the absence of any clinical signs of involvement of the salivary glands or of a history of exposure to a known case of mumps $^{3}$. It has been shown very recently that approximately 40 per cent. of the population may exhibit no clinically recognizable signs of infection with the mumps virus ${ }^{4}$. It thus becomes clear how it is possible to have mumps infection of the nervous system which cannot be traced to a known case of parotitis. Characteristically, infection of the human nervous system by mumps virus is associated with only mild clinical manifestations of aseptic meningitis (nuchal-spinal rigidity with predominantly mononuclear pleocytosis) and only rarely, if ever, are there signs of cerebral involvement to justify the diagnosis of encephalitis-a term which unfortunately is commonly and loosely used. Thus far, there is not a single fatal case in which death can be attributed to the primary effect of mumps virus on the nervous system, and the precise pathological changes produced by this virus in the nervous system are, therefore, unknown. In a patient with the clinical signs of aseptic meningitis, the diagnosis of mumps virus infection is most readily established by complement fixation tests on acute and convalescent serum specimens. The demonstration of the mumps virus in the cerebrospinal fluid of a suspected case is a more laborious procedure, but has been accomplished by several investigators in the last few years-on one occasion by inoculation of the fluid through Stensen's duct into the parotid gland of a monkey ${ }^{5}$ and, more recently with greater regularity, in at least seven cases by inoculation into the amniotic sac of the chick embryo ${ }^{6,7}$. It should be pointed out here that the only way one knows that mumps virus has been propagated in the chick embryo is by demonstrating the presence of specific hemagglutinating or, better still, complement-fixing antigen in the amniotic fluid or membrane.

The status of the relation of the virus of herpes febrilis or simplex to infection of the human nervous system has passed through at least three phases during the past 30 years. In the decade following 1920 , the occasional, admittedly rare, isolation of herpes virus from the brain of exceptional cases of encephalitis led to the serious consideration of this virus as the cause of von Economo's encephalitis lethargica by such renowned investigators as Levaditi ${ }^{8}$, Doerr ${ }^{9}$, Perdrau $^{10}$, Gay ${ }^{11}$ and their associates. The inadequacy of the evidence for this hypothesis was so strong, however ${ }^{12}$, that in the next decade it came to be regarded as highly improbable that the virus of herpes simplex was ever the primary cause of severe, apparent disease of the human nervous system. The question was reopened in
194I, when Smith, Lennette and Reames ${ }^{13}$ ڤ̊ demonstrated unequivocally, both by isolation of $\bar{D}$ the virus and the presence of acidophilic intra- $\underset{C}{c}$ nuclear inclusions in the patient's brain, that the virus of herpes simplex was indeed the cause of a fatal, acute encephalitis in a four-week-old child. Similar conclusive proof was provided in reports published in $1944^{14}$ and $1946^{15}$ on three additional $\frac{\bar{m}}{T}$ fatal cases, all of which occurred in adults aged 25 to 28 years. A nonfatal case of mild meningoencephalitis in a 15 -year-old boy with recovery of the virus from the cerebrospinal fluid and development of antibodies during convasescence was reported by Armstrong16 in 1943.

Clinically, the proved infections of the human nervous system by this virus were characterized $\exists$ by acute illnesses of 5 to 13 days' duration, i with severe manifestations including coma, con- is vulsions and focal muscular twitching pointing to $\mathscr{\omega}$ cerebral involvement. Since the strains of virus recovered from all these cases were highly pathogenic for mice, and since mouse inoculation has $\mathrm{O}$ been common practice during the past 15 years in many laboratories searching for etiological agents in infections of the human nervous system, these few reports may perhaps indicate that, while the virus of herpes simplex can unquestionably be ons of the causes of sporadic, acute encephalitis in man, it is perhaps not too frequent an occurrence Nevertheless, the frequency of its detection is undoubtedly dependent on one's alertness, for Dr. Margaret Smith of St. Louis recently informed me that she has recovered this virus from two additional fatal cases of acute encephalitis in adolescents. It is noteworthy that in not a single one of the proved cases of herpes simplex encephalitis reported thus far was there any evidence of herpetic eruption on the skin or mucous membranes.

Satisfactory evidence that the virus of lymphogranuloma venereum can give rise to severe meningoencephalitis in man was first brought forth in $1942^{17}$, with the complete identification of virus recovered on two occasions (four days and again 36 days after onset) from the cerebrospinal fluid of the same patient. It is noteworthy that, despite the severity and long duration of the neurological manifestations in this patient, the other clinical manifestations of lymphogranuloma venereum were negligible, although the same virus was recovered from insignificant vesicular lesions on the penis and from a slightly enlarged inguinal 0 lymph node. Infection due to this virus should be particularly suspected when the disease is drawn out over a period of weeks or months, and is $T$ associated with persisting pleocytosis and exceptionally high content of protein in the cerebrospinal fluid. In the patient just mentioned, con- 
centrations of protein up to $\mathrm{I}, 400 \mathrm{mg}$. per cent. were found more than two months after onset, and in another patient reported in 1944, who developed an adhesive arachnoiditis, as much as $3,570 \mathrm{mg}$. per cent. was present in the spinal fluid several months after onset ${ }^{18}$. The Frei test was negative in the first few months after involvement of the nervous system ${ }^{17,18}$, and, for diagnosis, reliance must be placed on complement fixation tests and isolation of the virus from the cerebrospinal fluid. Although there are some who would exclude lymphogranuloma venereum from the class of viruses, it is noteworthy that it is one of the very few agents in this group which have been found to be favourably affected by sulphonamides and more recently by the antibiotic, aureomycin ${ }^{19}$. An interesting instance of many recurrences of meningoencephalitis most likely due to lymphogranuloma venereum in a man, who was probably treated inadequately with sulphonamides was reported $^{20}$ in 1945 .

Among the diseases caused by viruses, whose basic reservoir is extra-human, is the large group of arthropod-borne encephalitides, recognized thus far only in certain parts of the world, and the group of diseases, including rabies, lymphocytic choriomeningitis, pseudolymphocytic choriomeningitis and $B$ virus, transmitted to man by the secretions or excreta of the animals which harbour them in nature. With regard to B virus infection I would merely like to say that thus far it has been recognized only as a fatal infection in two physicians who were either bitten by, or had a minor wound contaminated with the saliva of, apparently normal rhesus monkeys, which were being used as experimental animals. Early this year, for the second time since 1932, I recovered this virus from the axillary lymph node and nervous system of a young doctor who died of an encephalomyelitis following contamination of a cut on his finger by the oral secretions of rhesus monkeys with which he was working. Our present data suggest that the $B$ virus is carried by monkeys much as the virus of herpes simplex, to which, it is related antigenically, is carried by human beings ${ }^{21,22,23}$.

This completes the list of viral infections of the human nervous system in which the diseases are known and the viruses have been isolated and studied. In the next category we deal with known clinical entities, for which the viruses are either unknown or ill-defined, although a virus etiology is most likely on the basis of the pathological manifestations. In the case of von Economo's encephalitis lethargica, no etiological agent was established during the years when the disease was prevalent, and its relative rarity during the past 20 years has precluded any further work. The virus of herpes zoster has as yet not been transmitted to any experimental animal, and the problems concerning its relationship to the virus of varicella and the natural history and pathogenesis of the disease have received no significant elucidation in recent years. The virus recovered from Australian ' $\mathrm{X}$ ' disease, an epidemic encephalitis first recognized in Australia in 1917-1918 and not seen or recognized since $1926^{24}$, was unfortunately lost, but its known properties correspond most closely to the virus of Japanese $B$ encephalitis.

The next category, in which are listed at least eight viruses which have been reported since 1940, poses a special problem because while the viruses are all neurotropic in experimental animals, they have not as yet been definitely identified with any naturally occurring disease of the nervous system in human beings. Two of these viruses (West $\mathrm{Nile}^{25}$ and Bwamba Fever ${ }^{26}$ ) were recovered in Africa from the blood of natives suffering from a mild febrile illness, and serological surveys have suggested that infection with these viruses may not be uncommon in certain parts of Africa. The 'Semliki Forest'27 and 'Bunyamwera'28 viruses were isolated from wild-caught mosquitoes in Africa, the 'Ilheus'29 and 'Colombia Mosquito' viruses $^{30}$ from mosquitoes in South America, and the 'California Mosquito' virus from mosquitoese in North America ${ }^{31}$. Serological surveys have yielded suggestive evidence that most of these viruses recovered from mosquitoes have been responsible for inapparent or unrecognized infections in human beings. The latest virus to have been discovered in mosquitoes caught in the Mengo district of Uganda, Africa, and reported as the 'Mengo encephalomyelitis' virus ${ }^{32,33}$ has a particularly intriguing history, because (a) it has recently been proved to be immunologically identical with an agent, known as encephalomyocarditis or EMC virus, which was recovered in 1945 from chimpanzees in Florida and also with the so-called ' $M M$ ' and Columbia ' $S K$ ' viruses which have been erroneously called poliomyelitis viruses ${ }^{34}$; (b) recent serological surveys by Warren ${ }^{35}$ have shown that this virus is indigenous to rats in certain parts of the United States; (c) the Mengo virus was the cause of an illness which may have been encephalitis in one of the laboratory workers engaged in its investigation $^{32}$, and (d) although preliminary serological surveys in the United States and Africa indicated that this virus is not ordinarily disseminated among human beings, suggestive serological evidence was nevertheless obtained that it might have been the cause of an acute, short, febrile, non-fatal illness associated with signs of aseptic meningitis and occasionally coma in a small group 
of American soldiers in the Philippine Islands in $1946^{36}$. It seems to me that it is important for us to keep in mind two possibilities with regard to this new group of viruses. One is that their marked neurotropic property in experimental animals does not necessarily mean that they are predominantly neurotropic in man; in support of this possibility might be mentioned the fact that yellow fever virus is almost strictly neurotropic in the mouse and that recent work has shown that the virus of dengue fever is strictly neuronotropic in the mouse ${ }^{37}$ and predominantly so in the rhesus monkey ${ }^{38}$. Furthermore, $\mathrm{I}^{39}$ have recently found that the yellow fever and dengue viruses, which are so predominantly viscerotropic in man, are antigenically related not only to the West Nile virus which is a member of this new group, but also to Japanese B encephalitis virus which has been the cause of so many epidemics of encephalitis in human beings in Japan. The other possibility to keep in mind is that at least some of this new group of viruses may one day prove to be the cause of an extensive epidemic of encephalitis in human beings. It may be worth remembering that if by chance the virus of Western equine encephalomyelitis had been discovered in mosquitoes 20 to 30 years ago, we would have been in a similar quandary then; for, as it happened, although this virus was first recovered from horses in California in 1930 , it was not until 1941 that it caused the first recognized epidemic affecting over 3,000 people in West North-Central United States and the adjacent regions of Canada ${ }^{40,41}$.

In the final category of the classification presented here, I believed it necessary to list those diseases which are so frequently grouped with the virus infections but without any adequate evidence; among these may be mentioned infectious polyneuritis or the Guillain-Barré syndrome with all its numerous synonyms, the post-infection and post-vaccination demyelinating encephalitides and the so-called acute haemorrhagic encephalitis.

The specific diagnosis of the known viral infections of the nervous system still has many limitations. For example, there is still no simple laboratory test that can be used routinely for the specific diagnosis of infection with the virus which most commonly and universally affects the human nervous system, namely the virus of poliomyelitis. This perhaps is the reason for our failure, up to the present time, to account for the etiology of the major portion of cases diagnosed as aseptic or lymphocytic meningitis. However, great progress has been made in the past eight years in the development, purification and standardization of viral antigens for complement fixation. The accumulated experience of the last few years has indicated that the complement fixation test on acute and convalescent serum specimens now provides the simplest laboratory procedure for the routine, specific diagnosis not only of all the arthropod-borne virus encephalitides, but also of the infections caused by the viruses of mumps, lymphogranuloma venereum and lymphocytic choriomeningitis. Infection of the nervous system by the virus of herpes simplex can be established in the surviving patient only when recovery of the virus from the cerebrospinal fluid can be associated with the demonstrations that neutralizing antibodies for the virus either appeared or markedly increased in concentration during convalescence. The only known viruses which one may expect to recover with regularity from the cerebrospinal fluid of infected persons are those of mumps, herpes simplex, lymphogranuloma venereum and lymphocytic choriomeningitis.

The pathways by which viruses invade the central nervous system and spread within it have received extensive experimental investigation in the attempt to elucidate the pathogenesis of the diseases resulting from such invasion. The results available thus far, which are much too extensive for detailed review in this communication, indicate that the cellular affinities of a given virus and the level of multiplication it may attain in certain susceptible cells can determine not only the path ways of invasion, but also the extent of its spreas -and accordingly can vary not only in different $t^{+}$ species of animals, but also in the same species depending on age, nutrition or genetic constitution of the host ${ }^{42}$. The property which differentiates the spread of the true neuronotropic viruses, i.e. those actually multiplying within the neurones, from that of all other infectious agents, is concerned with the capacity of these viruses to spread along insulated tracts not only in the axonal processes of the neurone, but also across the synapses from one special group of neurones to another ${ }^{43}$ The capacity of a virus to move centripetally along an axon to the cell body of the neurone has been shown to depend on certain influences emanating from the cell body rather than on simple diffusion, since it was found that such a virus could move neither in the axons nor in other portions of nerve fibres which had been severed from the cell bodies of the neurones, but retained their blood and lymph supplies. It has also been found that the incubation period in such instances is determined not by the length of the nerve fibre, that is to say not by the distance which it has to travel, but rather by (I) a latent period before it begins to spread, and (2) the time between invasion of the cell bodies of the neurone and the appearance of sufficient damage to give rise to clinical signs - and both of these latter factors can vary considerably even for closely 
related viruses ${ }^{44}$. A remarkable example of a closed pathway pursued by some viruses across synaptic junctions within the central nervous system is to be found in the behaviour of vesicular stomatitis or eastern equine encephalomyelitis virus after injection into the vitreous of the eye of a mouse $^{45}$. These viruses produce necrosis of the nerve cells they attack and their earliest progression can be followed by tracing these lesions in serial sections. As may be seen in the accompanying illustration (Fig. I), the virus destroys the nerve cells in the retina of the inoculated eye and progressing along the insulated, decussating fibres in the optic chiasm produces necrosis only in the contralateral superior colliculus. Necrosis can be produced either in the right or the left superior colliculus depending on which eye is inoculated with the virus; it should, furthermore, be noted that the neurones through which the fibres of the optic tract pass on the way to the superior colliculi remain intact and that no necrosis of the superior colliculi is found in animals which develop encephalitis after inoculation of the virus by any other route. It is also noteworthy that not all neuronotropic viruses invade along the same pathway from the same site in the same host. Thus, pseudorabies virus introduced into the mouse's eye invades the brain along the sympathetic, parasympathetic and ophthalmic sensory fibres rather than along the decussating optic pathway. Similarly while some viruses (e.g. vesicular stomatitis, equine encephalitis, St. Louis encephalitis, rabies, etc.) after nasal instillation invade the central nervous system only along the olfactory pathway, other viruses like those of herpes simplex and pseudorabies can invade along the trigeminal sympathetic and parasympathetic pathways without utilizing the olfactory pathway ${ }^{46}$. The importance of the host is strikingly exemplified by the different behaviour of eastern equine encephalitis in mice, guinea-pigs ${ }^{47}$ and monkeys ${ }^{48}$-in mice the centripetal spread is invariably along some neuronal pathway while in monkeys and guinea-pigs, with rare exceptions, the central nervous system appears to be invaded from the blood by a growth of the virus directly across the blood vessels.

From what has just been said, it must be apparent that the behaviour of some of these viruses in human beings cannot be deduced from observations on experimental animals. With regard to at least three viruses which affect the human nervous system, namely, mumps, lymphogranuloma venereum and lymphocytic choriomeningitis, there is no evidence that they multiply in the neurones, and it is therefore most likely that they invade the choroid plexus and meninges across the blood vessels. On the other hand, in the case of poliomyelitis and rabies, there is as yet* no confirmed evidence that these viruses can multiply in any cells other than the neurones, and the available data is all in favour of the hypothesis that in human beings these viruses invade and spread by neuronal pathways ${ }^{40,50}$. The severe generalized encephalitis and widespread cerebral lesions in the proved fatal human infections due to herpes simplex virus, thus far have given no clue to the mode of invasion and spread of this virus. On the other hand, in the fatal human infections due to the related monkey ' $B$ ' virus, the evidence strongly suggested invasion and spread along neuronal pathways. All the arthropod-borne encephalitis viruses are to varying degrees both viscerotropic and neuronotropic, and the diffuse cortical lesions which have been observed in fatal human cases $^{51,52,53}$ strongly suggest that the nervous system may be invaded from the blood by a 'growth' of these viruses directly across the blood vessels.

One of the most striking phenomena in relation to most of the viruses which affect the human nervous system is that only a small and varying proportion of individuals who become infected ever exhibit clinical signs of involvement of the nervous system. In the case of poliomyelitio throughout the world and in the case of Japanese $B$ encephalitis in certain endemic regions, it hat been possible to show by means of serological tests that beyond a certain age almost every person had at one time or another been infected with these viruses. In some parts of the world where this obtains there are occasional large-scale epidemics of clinically manifest poliomyelitis or encephalitis while in others clinically recognized cases are extremely rare among the native populations and epidemics of these diseases are unknown. Korea is a striking illustration for both poliomyelitis and Japanese B encephalitis ${ }^{53}$. Serological surveys which we have carried out in Korea indicated that roo per cent. of the population, five years of age or older, had antibodies for the Lansing strain of poliomyelitis virus ${ }^{54}$, and 80 to 100 per cent. of the population, over ten years of age, had antibodies for the Japanese $\mathrm{B}$ encephalitis virus ${ }^{55}$. And yet no epidemics of either poliomyelitis or encephalitis $\uparrow$ have occurred in the native population

* See Enders, J. F., Weller, T. H., and Robbins, F. C., "Cultivation of the Lansing strain of poliomyelitis virus in cultures of various human embryonic tissues,' Science, I949, Io9, 85-87; and Weller, T. H., Robbins, F. C., and Enders, J. F., 'Cultivation of poliomyelitis virus in cultures of human foreskin and embryonic tissues,' Proc. Soc. Exp. Biol. Med., 1949, 72, I 53-1 55 .

† Information transmitted to the Commission on Virus and Rickettsial Diseases, U.S. Army Epidemio(Continued at foot of next column) 
and sporadic cases are rare or unknown among them, although small outbreaks of both diseases have by now occurred among American soldiers stationed in their midst. China is another country with a very high incidence of inapparent infection ${ }^{56}$ while Japan across the sea has suffered many large epidemics of Japanese B encephalitis, the last one in 1948 with approximately 8,000 reported cases. For years our inquiring spirit and curiosity with respect to this problem has been deadened by the explanation, which has no experimental foundation, that repeated exposure to small subinfective doses of virus (i.e. amounts too small to undergo multiplication) can give rise to an immunity which permits the host to resist subsequent infection with larger doses. It has become increasingly evident, however, in recent years that the situation may actually perhaps be the other way around; namely, that the reason many individuals have immunity without known history of disease is that upon first exposure to an infective dose their tissues were so constituted as to keep viral multiplication down to a low level or successfully to halt its dissemination.

The most striking experimental evidence of the

logical Board, of which the author is a member, indicated that an epidemic of acute encephalitis affecting over 5,000 natives, with a case fatality rate of 44 per cent., occurred in Southern Korea during September 1949. Work on the etiology of this epidemic is still in progress. dependence of clinical manifestations on the level of viral multiplication, and of the dependence of the level of viral multiplication on the constitution of the host cells was supplied by Webster ${ }^{57}$ in his studies on the behaviour of the virus of St. Louis encephalitis in two very slightly different genetic breeds of mice. In the resistant variety, which remained well after intracerebral inoculation, the virus also multiplied but reached only one thousandth of the concentration of that achieved in the susceptible mice which died of encephalitis. Various other types of resistance, in which age and diet are contributing factors, have also been brought to light by experimental work in recent years ${ }^{42}$.

The possibility of controlling the epidemic viral infections of the human nervous system by means of vaccines, even where good ones could be prepared, seems to be most impractical except under special circumstances, first, because the immunity produced by them takes too long to develop and is too short-lived, and secondly, because such epidemics are of short duration and occur at varying and unpredictable intervals. For this reason it becomes most important to search for compounds, which might so affect the metabolism of the susceptible nerve cells that viruso multiplication could be kept down to the sub? clinical level without jeopardizing the life of the cell. Our ultimate ability to control these diseases may well depend upon the success of this search.

\section{REFERENCES}

I. ENDERS, J. F., and COHEN, S. (1942), Proc. Soc. Exp. Biol. and Med., $50,180$.

2. ENDERS, J. F., KANE, L. W., COHEN, S., and LEVENS, J. H. (1945), भ. Exp. Med., 81, 93.

3. KANE, L. W., and ENDERS, J. F. (1945), F. Exp. Med.,81, 137.

4. MARIS, E. P., ENDERS, J. F., STOKES, J. Jun., and KÁNE, L. W. (1946), F. Exp. Med., 84, 323.

5. SWAN, C., and MAWSON, J. (1943), Med. F. Austral., 1, 411 .

6. HENLE, G., and MCDOUGALL, C. L. (1947), Proc. Soc. Exp. Biol. and Med., 66, 209.

7. KILHAM, L. (1948), Proc. Soc. Exp. Biol. and Med., 69, 99.

8. LEVAdITI, C. and HARVIER, P. (1920), Ann. Inst. Past., 34, 911 .

9. DOOERR, R., and SCHNABEL, A. (1921), Zeitschr. f. Hyg. u. Infektionskr., 94, 29.

10. PERDRAU, J. R.'(1925), Brit. F. Exp. Path., 6, 123.

II. GAY, F. P., and HOLDEN, M. (I929), F. Infect. Dis., 45, 415

12. FLEXNER, S. (1935), Proc. Inst. Med. Chicago., 10, 278.

13. SMITH, M. G., LENNETTE, E. H., and REAMES, H. R. (1941), Am. F. Path., 17, 55.

14. ZARAFONETIS, C. J. D., SMADEL, J. E., ADAMS, J. W. and HAYMAKER, W. (I944), Am. f. Path., $20,429$.

15. WHITMAN, L., WALL, M. J., and WARREN, J. (1946), 7. Am. Med. Assn., 131, 1408.

16. ARMSTRONG, C. (1943), Pub. Health Rep., 58, 16

17. SABIN, A. B., and ARING, C. D. (1942), भु. Am. Med. Assn., I20, 1376.

18. ZARÁFONETIS, C. J. D. (1944), New Eng. F. Med., 230, 567. 19. WONG, S. C., and COX, H. R. (1948), Ann. N. Y. Acad. Sc.,

51, 290. SCOTT, D. W., JUn. (1945), Arch. Int. Med., 76, 174

21. SABIN, A. B. (1934), Brit. F. Exp. Path., 15, 248.

22. BURNET, F. M., LUST, D., and JACKSON, A. V. (1939), Austral.' '. Exp.'Biol. and Med. Sc., 17, 41.

23. SABIN, A. B. (1949), unpublished.

24. KNEEBONE, J. LEM., and CLELAND, J. B. (1926), Austral. F. Exp. Biol. and Med. Sc., 3, I19.

PERDRAU, J. R. (1936), F. Path. Bact., 42, 59.

25. SMITHBURN, K. C. (I942), Ұ. Immunol., 44, 25

26. SMITHBURN, K. C., MAHAFFY, A. F., and PAUL, J. H. (1941), Am. F. Trop. Med., 21, 75.
27. SMITHBURN, K. C., and HADDON, A. J. (1944), $\mathcal{f}$. Immunol., 49, 141 .

28. SMITHBURN, K. C., HADDON, A. J., and MAHAFFY, A. F. (1946), Am. F. Trop. Med., 26, I89.

29. LAEMMERT, H. W., and HÜGHES, T. P. (1947), $\mathcal{F}$ Immunol., 55, 6I.

30. ROCA-GARCIA, J. (1944), F. Infect. Dis., 75, I60.

31. HAMMON, W. M., and REEVES, W. C. (1945), Am. F. Pub Health, 35, 994.

32. DICK, G. W. A., HADDOW, A. J., BEST, A. M., and SMITHBURN, K. C. (1948), Lancet, 2, 286.

33. SMITHBURN, K. C. (1948), Proc. 4th Internat. Cong. Trop. Med. and Malaria, $\mathrm{I}, 576$.

34. WARREN, J., SMADEL, J. E., and RUSS, S. B. (1949), $\mathcal{f}$ Immunol., 62, 387.

DICK, G. W. A. (1949), Ibid., 62, 375

35. WARREN, J., RUSS, S. B., and JEFFRIES, H. (1949), Proc. Soc. Exp. Biol. Med., 71, 376.

36. SMADEL, J. E., and WARREN, J. (1947), f. Clin. Invest. 26, 1197.

37. SABIN, A. B., and SCHLESINGER, R. W. (1945), Science, IOI, 640 .

38. SABIN, A. B. (1949), Viral and Rickettsial Infections of Man, J. B. Lippincott Co., Philadelphia.

39. SABIN, A. B. (1949), Fed. Proc., 8, 410.

40. LEAKE, J. P. (I94I), Pub. Health Rep., 56, 1902.

40. LEAKE, J. P. (I94I), Pub. Health Rep., 56, 1902.

42. SABIN, A. B. (1941), Ұ. Pediat., I9, 596.

43. SABIN, A. B., and OLITSKY, P. K. (1937), Am. F. Path.

44. SABIN, A. B. (1937), Am. F. Path., 13, 6r5; also unpublished observations.

45. SABIN, A. B., and OLITSKY, P. K. (1938), F. Exp. Med., 67, 201.

46. SABIN, A. B. (1938), Proc. Soc. Exp. Biol. and Med., 38, 270 47. SABIN, A. B., and OLITSKY, P. K. (1938), Proc. Soc. Exp. Biol. and Med., 38, 595.

48. HURST, E. W. (1936), Ұ. Path. and Bact., 42, 27 I.

49. SABIN, A. B., (1944), Ұ. Mt. Sinai Hosp., I1, 185.

(Continued on page 155 ) 
50. SABIN, A. B. (1949), Ann. Int. Med., 30, 40.

51. ZIMMERMAN, H. M. (1946), Am. Ұ. Path., 22, 965.

52. HAYMAKER, W., and SABIN, A. B. (1947), Arch. Neur. and Psych., 57,673.

53. SABIN,' A.' B., SCHLESINGER, R. W., GINDER, D. R., and MATUMOTO, M. (1947), Am. 7 . Hyg., 46, 356 .

54. SABIN, A. B., and YOUNG, I. Unpublished.

55. DEUL, R. E., BAWELL, M. B., MATUMOTO, M., and SABIN, A. B. (1950), $A m$. $\mathscr{F}$. Hyg., in press.

56. SABIN, A. B., SCHLESINGER, R. W., and GINDER, D. R.' (1947), Proc. Soc. Exp. Biol. and Med., 65, 183 .
57. WEBSTER, L. T., and CLOW, A. D. (1936), f. Exp. Med., WEBSTER, L. T., and JOHNSON, M. S. (1941), f. Exp. Med., 74,489

58. MEL ${ }^{789}$. $K$, J. L., SHAW, E. W., and CURNEN, E. C. (1949), Proc. Soc. Exp. Biol. Med. 7I, 344.

59. DALLDORF, G., SICKLES, G. M., PLAGER, H., and GIFFORD', R. (1949), 7. Exp. Med., 89, 567.

6o. DALLDORF, G. (1949), Science, I10, 594. 6o. DALLDORF, G. (1949), Science, I10, 594. (1949), Proc. Soc.
6I. SICKLES, G. M., and DALLDORF, G. (1949). Biol. Med., 72, 30.

\section{FELLOWSHIP OF POSTGRADUATE MEDICINE \\ I Wimpole Street, Lomdon, W.I}

THE ANNUAL GENERAL MEETING will be held at the above address at 5.0 p.m. on Wednesday, April 19, 1950. The Meeting is open to all Members of the Fellowship of Postgraduate Medicine, but not to those who subscribe only to the Postgraduate Medical Journal.

\section{$\boldsymbol{A} \boldsymbol{G} \boldsymbol{E} \boldsymbol{N} \boldsymbol{A}$}

1. To read the Minutes of the last Annual General Meeting.

2. To (a) receive the Reports of the Hon. Treasurer and Hon. Secretaries.

(b) elect (i) The Honorary Officers*;

(ii) Seven Members* to serve on the Executive Committee;

(iii) The Auditors.

3. Any other business.

* Nominations for the Honorary Officers and for the elected Members of the Executive Committee must be sent to the Honorary Secretaries by March 16, 1950.

by S. LEONARD SIMPSON, M.D., F.R.C.P.

Physician to Willesden General Hospital, with Charge of Diabetic and Endocrine Clinics ; Endocrinologist to Princess Louise Children's Unit of St. Mary's Hospital ; Consulting Physician and Endocrinologist to the Soho and Samaritan Hospitals for Women.

'The style of the book is throughout stimulating and thought-provoking.' -British Medical Journal.

'The best work of its kind we have seen in recent years.'-Clinical Journal.

'An admirable introduction and guide to a difficult subject.'-Postgraduate Medical Journal. 